\title{
LA POLÍTICA DEL RECHAZO. PENSAMIENTO POLÍTICO EN MAURICE BLANCHOT
}

\section{POLITICS OF REFUSAL. MAURICE BLANCHOT POLITICAL THOUGHT}

\author{
Idoia QUINTANA DOMÍNGUEZ* \\ Universidad de Deusto
}

Resumen: Las nociones de rechazo y de revolución atraviesan diferentes épocas del pensamiento político de Blanchot. En este artículo caracterizamos brevemente estas nociones en los años 30 para pasar a analizar cómo son desarrolladas a partir de los 50 . Destacaremos la originalidad de la búsqueda de un tipo de poder capaz de poner todo poder en cuestión sin que se constituya y opere como fundamento. Se esbozará así un espacio liminar frente a la política. En la última parte abordaremos la crítica de Nancy a una política que se presentaría a la vez como una política de lo imposible y como una política imposible.

Palabras Clave: Maurice Blanchot, política, rechazo, revolución, comunidad, JeanLuc Nancy.

AвSTRACT: The notions of refusal and revolution exist throughout different time periods in Blanchot's political thinking. This article will first briefly characterize these notions during the 1930s to go on to analyze how they are developed from the 1950s onward. We will highlight the originality of the search for a kind of power capable of questioning all power without having to be constituted and to operate as a foundation. Thus, a liminal space as opposed to politics will be suggested. In the last part, we will address Nancy's critique of a type of politics that would be presented both as politics of the impossible and as impossible politics.

\footnotetext{
*Idoia.quintana@deusto.es. Investigadora posdoctoral del Centro de ética aplicada a la realidad social de la Universidad de Deusto. Artículo elaborado en el marco del Programa Posdoctoral de perfeccionamiento de doctores del Gobierno Vasco.
} 
KeYwords: Maurice Blanchot, politics, refusal, revolution, community, Jean-Luc Nancy.

\section{Introducción: abandono de la torre de marfil}

En un determinado momento, por unas causas concretas, el escritor debe recorrer el camino que le separa del espacio público sin franquear no obstante esa separación, pues debe guardar ante la política una proximidad que lo mantenga a distancia. Así describe Blanchot al intelectual, posicionándose él mismo en el lugar del escritor que se expuso a habitar temporalmente en ese lugar precario que no se limita a la acción o al poder político sino que demanda de él una exigencia que no es la del simple compromiso (Blanchot, 2010).

Esta referencia a la necesidad de que el escritor abandone su soledad, o su «torre de marfil» (Blanchot, 1932 b, 1), es una vieja inquietud de Blanchot que ya se dibujaba en sus primeros escritos de los años 30 y que vuelve a ser retomada en una de sus últimas obras. "¿Los escritores deben desinteresarse de la política y sustraer su pensamiento de una actividad que no los concierne más que indirectamente y que puede ser comprometedora?» (Blanchot, $1932 \mathrm{~b}, 1$ ), preguntaba Blanchot en 1932; "¿Qué clase de mandamiento exterior es ese al que debe responder, que le obliga a incorporarse al mundo y asumir una responsabilidad suplementaria que puede acabar perdiéndole?» (Blanchot, 2010, 405), preguntará en 1984. Las motivaciones que llevan al escritor a adentrarse en un terreno que no es el suyo difieren profundamente en ambos periodos. En los 80, es la injusticia la que reclama al intelectual, «se anuncia, se agita y se remueve cuando, en casos precisos, la justicia le parece alcanzada o amenazada por las autoridades superiores» (Blanchot, 2010, 394). En los años 30, es en nombre del orden y de la estabilidad de una herencia espiritual por lo que el escritor, más que cualquier otro, está llamado a actuar obedeciendo un requerimiento de adecuación con una identidad suplementaria, una identidad que señala hacia una instancia dictada por un "orden verdadero», el destino y los valores que dan sentido a la civilización ${ }^{1}$.

\footnotetext{
${ }^{1}$ «Le convendría ser sensible a los signos del desastre que amenazan la herencia de nuestra civilización y que le minarían a él [el escritor], heredero privilegiado, más que a cualquier otro». BLANCHOT, M. (1932 a). «Le Rajeunissement de la politique», Journal des débats, 2 de mayo, p. 1. «En una época en la que los valores espirituales están amenazados, al mismo tiempo que los bienes más concretos, este interés por la política que manifiestan los intelectuales es como un interés por su destino y un recordatorio de las condiciones elementales de
} 
Es sabido que el Blanchot de los años 30 rechazó enérgicamente las diversas figuras que se presentaban como capaces de encarnar el poder político. Ni nazismo, fascismo, comunismo o democracia, como tampoco la figura de un líder eran vistas como soluciones a una crisis de orden político. Leslie Hill condensa la posición de Blanchot frente a la pregunta por cómo «refundar el orden político anudando la legitimidad política a tal o cual figura de la autoridad soberana. [...] Individuo, nación, partido, ideología o clase - ¿quién era el verdadero sujeto de la política?» (Hill, 2014, 54). Esta pregunta se imponía en una crisis que si era de orden político, lo era porque se creía que en ese ámbito se debía poner en juego el orden de lo espiritual o el destino de la civilización (Cf. Nancy, 2011, 24-25). Crisis que era al mismo tiempo también una crisis de fundación de lo político y del orden que pudiera orientar, autorizar y justificar la acción política. La apuesta de Blanchot no fue otra que la de asociar ese lugar fundacional y de destino al de una figura vacía pero imponente,

la única figura que quedaba, todavía ausente y separada de ella misma, todavía hurtada por una abyección humillante, pero de la que se esperaba con fervor que pudiera reencarnarse, presente, inmediata y sublime, como una obra de arte: la nación francesa misma. (Hill, 2014, 55).

Y en nombre de esta figura, de su restauración-fundación, justificaba, autorizaba y llamaba a la acción violenta. La revolución proclamada por Blanchot como salida del «desorden establecido» se define como un elemento del azar que completa un orden necesario, es decir, un orden ya fundado según un modelo del futuro anterior ${ }^{2}$, mientras que el rechazo al orden imperante se describe como un acto de purificación que devuelve al sujeto que rechaza a sí mismo, borrando de él todo lo contingente ${ }^{3}$. En estos años hay en Blanchot una persistencia en el

estabilidad y de orden sin las cuales las obras más bellas del espíritu son vanas». BLANCHOT, M. (1932 b). «Les Écrivains et la politique», Journal des débats, 27 de julio, p. 1.

2 «De lo improvisada que era [la revolución], furtivamente introducida en lo real, débil intervalo en la sucesión rigurosa de combinaciones establecidas, se vuelve la realidad más dura, presencia inalienable e incoercible; extrae de su origen contingente un máximo admirable de existencia definitiva, probando sin cesar a los que la han negado que es el pasaje brusco de lo imposible a lo necesario». BLANCHOT, M., (1933). "Le Marxisme contre la révolution", La Revue française, $\mathrm{n}^{\circ}$ 4, 25 de abril, p. 516.

${ }^{3}$ «[...] el espíritu rebelde busca obstinadamente [...] algo que le sea propio y que le exprese. [...] se apoya en sí mismo, toma contacto consigo mismo, no como una conciencia desnuda, sino como con una armonía concreta, el universo más real reducido a un punto. Ahora detenta al mismo tiempo lo que debe defenderlo y lo que le hace defender. Su rechazo hace que se desprenda de sí todo lo que no es su persona, le manifiesta como una existencia personal cuyo 
requerimiento de la instauración del poder en el orden del Estado en una adecuación entre orden y Estado. Pero al mismo tiempo la idea de nación se describe como un exceso, difícilmente encarnable, que relanza al infinito la manifestación de un orden superior, principio a la vez de identidad, de reunión, de fusión, como también de elevamiento de la figura de lo único y sobre-individual. La nación en sí misma se presenta como el proceso infinito de su manifestación mítica, la revolución como el proceso permanente para devolver la nación a sí misma y el rechazo como el acto de entrega personal a un destino heroico de desvelamiento subjetivo. El orden político no podía más que obedecer de ese modo a un orden que lo trascendía y del cual la política debía extraer su verdad y una orientación para la acción ${ }^{4}$.

Cuando en 1958 Blanchot se sienta llamado a intervenir en el ámbito de la política será porque de Gaulle representa en buena medida aquel poder providencial que años atrás exaltaba. Su reflexión política dejará de estar orientada por el astro de la nación, mientras que las nociones de revolución y de rechazo, a pesar de la persistencia en el uso de estos términos, sufrirán un cambio decisivo y serán atravesadas por una problematización profunda del sujeto, de la acción y de la historia a través de nociones como las de lo neutro o la pasividad, elaboradas fundamentalmente a partir de los ańos 60 , paralelamente a unos acontecimientos políticos que marcarán profundamente su pensamiento.

cumplimiento es el objeto último y la salvaguarda del rechazo mismo». BLANCHOT, M. (1933). «Le Marxisme contre la révolution», La Revue française, n4, 25 de abril, pp. 506517.

${ }^{4}$ Sobre la noción de revolución en Blanchot en los años 30, remitimos al debate entre JeanLuc Nancy y Étienne Balibar (2014). «Discussion entre Étienne Balibar et Jean-Luc Nancy», Cahiers Maurice Blanchot, n³, Dijon: Les presses du réel, pp. 20-28. Desde una perspectiva biográfica de los años 30, a la carta de Blanchot publicada y prologada por Jean-Luc Nancy (2011). Maurice Blanchot. Passion Politique, París: Galilée, pp. 47-62 y a la biografía de Christophe Bident (1998). Maurice Blanchot. Partenaire invisible, Seyssel: Champ Vallon. La bibliografía sobre los ańos 30 de Blanchot comienza a ser abundante. Entre esta, destacamos las siguientes obras en las que se da cuenta desde perspectivas muy diversas de la trayectoria política de Blanchot: MESNAND, Ph. (1996). Maurice Blanchot. Le sujet de l'engagement, París: L'Harmattan; SURYA, M. (2015). L'autre Blanchot, París: Gallimard; MARTÍNEZ GONZÁLEZ, R. (2014). Maurice Blanchot: la exigencia politica, Zaragoza: Prensas Universitarias. Asimismo, la revista Lignes en el número de marzo de 2014 publicó una recopilación de artículos sobre Blanchot y la política, Les politiques de Maurice Blanchot 1930-1993. Para un análisis histórico, LOUBET DEL BAYLE, J.-L. (1969). Les Non-Conformistes des années 30, París: Seuil y VERDÈS-LEROUX, J. (1996). Refus et violences, París: Gallimard. 
En lo que sigue, a través de varios textos y momentos de su obra, veremos cómo a partir de los ańos 50 el pensamiento político de Blanchot se despliega en torno a las nociones de rechazo y revolución, y cómo a partir de estas nociones Blanchot da cuenta de un poder de insubordinación al orden político que no se constituye como poder. Su mot d'ordre podría ser: «no instituir, no instituirse».

\section{Rechazo e insumisión}

De Gaulle va a representar para Blanchot la perversión esencial de la política. En un clima de gran inestabilidad, quien durante la ocupación había personificando «la presencia visible de una gran nación ausente» (Blanchot, 2001, 20), reaparece en mayo de 1958 colmando esa misma ausencia. Cuando Blanchot denomina como perversión esta llegada al poder, no lo hace porque esta figura asuma la totalidad de los poderes bajo un ejercicio del poder soberano. Esta perversión esencial la localiza a un nivel más profundo, pues se sitúa más bien en que el poder que reposa sobre De Gaulle no es de orden político, no es un poder ejercido, sino un poder providencial, poder de salvación, omnipotente e inmediato. De Gaulle no representa al país sino que lo hace « legible y lejanamente presente en su realidad intemporal» (Blanchot, 2001, 19).

El destino está ahora en el poder: no el de un hombre históricamente destacable, sino una potencia que está por encima de la persona, la fuerza de los valores más elevados, la soberanía, no una persona soberana, sino la soberanía misma, en la que se identifica con las posibilidades reunidas de un destino. (Blanchot, 2001, 20)

De Gaulle no encarna el poder soberano, sino que ocupa el lugar que concede poder sagrado a la soberanía. El espacio político pasa a ser el espacio ocupado por la nación como destino y De Gaulle el símbolo de una salvación que por su llegada al poder, no por medio de la decisión sino de la providencia, se presenta como una figura de autoridad incapaz de acción y de decisión. Con De Gaulle, denuncia Blanchot, la soberanía se sostiene sobre el fundamento de un poder providencial, «de esencia religiosa» (Blanchot, 2001, 23) y en esta sacralización del poder localiza el gesto antipolítico por excelencia.

Blanchot describe esta usurpación del poder político en el tercer número de la revista Le 14 Juillet a la que Dionys Mascolo le invitó a participar y a la que respondió con un acuerdo firme. Previamente a este extenso artículo donde 
advierte de los peligros de una inédita transformación del poder, titulado «La perversión esencial», Blanchot pronuncia un término clave en su reflexión que define el lugar desde el que se situará ante esta política, el término "rechazo»: «En un determinado momento, frente a los acontecimiento públicos, sabemos que debemos expresar nuestro rechazo. El rechazo es absoluto, categórico. No discute ni hace escuchar sus razones» (Blanchot, 2001, 12). Este rechazo se describe como silencioso y solitario, no une como puede unir una afirmación, sino que liga a quienes rechazan a través de la «amistad de ese 'No' convencido, inquebrantable, riguroso" (Blanchot, 2001, 12). Este rechazo se va a caracterizar por constituir un tipo particular de poder que no emana de quienes lo enuncian, sino que expresa una fuerza anónima, la fuerza de una palabra que no puede poseerse a sí misma y cuyo origen Blanchot no sitúa en el lugar abstracto de un valor universal sino en «un comienzo muy pobre que pertenece en primer lugar a aquellos que no pueden hablar» (Blanchot, 2001, 13).

La noción de rechazo, radicalmente diferente del sentido que le atribuía en los años 30, será central en el pensamiento político de Blanchot. A principios de los años 60 podemos encontrar una definición del rechazo en un texto aparentemente más filosófico que político: «no que pone en tela de juicio todo poder constituido, y pone también en tela de juicio el poder de decir no, designándolo como lo que no tiene su fundamento en un poder, como irreductible a todo poder y, en este sentido, no fundado" (Blanchot, 2008, 37). El rechazo es por lo tanto poder de poner todo poder constituido en cuestión sin que este poder se constituya y opere como fundamento, lo que en otros textos se denominará como un "poder sin poder" 5 .Afirmación que no ordena sino que desordena y se desordena, pues guarda relación con el trastorno y el desasosiego, o incluso con lo no-estructurable» (Blanchot, 2001, 102), dirá más tarde, durante el 68. El rechazo pone en cuestión el orden político, pero en ese poner en cuestión o trastornar, ¿qué tipo de relación establece el rechazo con la política?

En el artículo «La política de lo fragmentario», Leslie Hill define el rechazo como constitutivo de la política: «la posibilidad del rechazo [...] es constitutiva de toda política como tal» (Hill, 2014, 53). En este sentido afirma que no habría

\footnotetext{
${ }^{5}$ Entre otros, en la carta dirigida a Jean-Paul Sartre en 1960, después de la redacción de la «Declaración sobre el derecho a la insumisión en la guerra de Argelia»: «Los intelectuales han tomado así conciencia del nuevo poder que representan y, aunque de manera confusa, de la originalidad de ese poder (poder sin poder)». BLANCHOT, M. (2001). Escritos politicos, trad. de Lucas Bidon-Chanal, Buenos Aires: Libros del Zorzal, p. 45.
} 
política legítima que no contenga la posibilidad del rechazo, es decir, que no contenga como posibilidad el paso por su propia interrupción -cuestionamiento total del poder constituido-, es decir, que no contenga como elemento fundamental la posibilidad de un suspenso soberano que sería el único capaz de otorgar legitimidad y no simplemente legalidad a un orden político determinado. Según este autor, el rechazo tendría de este modo una función legitimadora, orientada a velar por una política a la que mostraría su falta de fundamento último o la contingencia de su fundamento. Si aquí el término "constitutivo» parece problemático al ser asociado a un rechazo que se caracteriza por no constituir ni constituirse es porque precisamente el rechazo no va a jugar tanto un papel operativo e interno a la política-legitimador o legitimidad son palabras que nunca aparecen en los textos de Blanchot- como una resistencia que excede la política. No obstante, que exceda la política significa que la politica está y debe estar en relación con lo que la excede. Quizá sea esta relación, ya que es precisamente la relación entre la política y lo que esta no puede contener por ser del orden de lo indeterminado, imprevisto y no fundado o capaz de fundar, la que Leslie Hill señala cuando se refiere al rechazo como constitutivo o fundador.

Este espacio liminar también podría verse en la reivindicación de la insumisión como derecho soberano frente a la soberanía política ${ }^{6}$. En Que faire, JeanLuc Nancy habla de un límite de la política cuando se refiere a que el principio de la soberanía política es inseparable de otro principio, «el principio de una insubordinación también soberana» (Nancy, 2016, 40). Nancy cita la "Declaración universal de los derechos del hombre» de 1948 donde se dice que cuando un régimen de derecho se vuelve tirano y opresivo, el hombre está obligado, como supremo recurso, a la revuelta contra el régimen. En una entrevista donde Blanchot explica lo que había sido dicho en la «Declaración sobre el derecho a la insumisión en la guerra de Argelia» de 1960, de la que había sido uno de los principales redactores y cuya originalidad residió precisamente en asociar el derecho a la insumisión con el rechazo, sin hacer ninguna alusión a las Declaraciones universales, Blanchot se expresa casi en los mismos términos, sustituyendo «supremo recurso» por «recurso fundamental» $\mathrm{y}$ «recurso último»: «el derecho

\footnotetext{
${ }^{6}$ La noción de insumisión es central no solo en «La declaración sobre el derecho a la insumisión en la guerra de Argelia", sino también en textos posteriores que vuelven sobre este manifiesto donde se define como un derecho fundamental mantenido sobre el rechazo. En "Blanchot l'insoumis", Blanchot dans son siècle, Lyon: Sens Publique, 2009, pp. 289-314, Étienne Balibar realiza una lectura detallada de esta noción y de la Declaración, interrogándose sobre el carácter de este derecho que excedería e interrumpiría todo derecho constituido, como derecho anterior a todo derecho.
} 
de rechazar [...]. Es el recurso fundamental [...] el recurso último como poder de decir 'No'" (Blanchot, 2001, 36). Nancy, en su escrito, concluye su reflexión sobre el «principio de insubordinación» afirmando: «De esta manera, el pueblo excede siempre la política. [...] Hay un principio de identidad política (¿o bien metapolítica?) según el cual el poder no puede (es su férreo impoder) destruir, disolver o devorar aquello sobre lo que se ejerce. A menos de renunciar a sí mismo» (Nancy, 2016, 41).

El principio de «insubordinación soberana», que se podría pensar como solidario del de insumisión y rechazo, indica, por una parte, una soberanía que excede la soberanía política (Nancy habla del pueblo, y más tarde veremos la resonancia que esta palabra tiene también en Blanchot) y, por otra parte, como consecuencia de lo anterior, el impoder mismo de la política, lo que Nancy define como su propio límite o incluso como su propia condición de posibilidad hasta afirmar que solo si atiende a este impoder, la política es política y no otra cosa — una tiranía - (lo que difiere de afirmar que este impoder "constituya» la política), y sobre el que Blanchot señalará continuamente que es la impotencia de la política para alcanzar aquello que no puede circunscribir.

En consecuencia el rechazo sería, como afirmaba Hill, constitutivo de la política pero solo en el sentido de delinear su límite o su impoder (Nancy), su limitación o su impotencia (Blanchot), pues el rechazo es lo que excede la política. El rechazo ni se instituye ni se reivindica simplemente como un paso previo a la institución de derechos o de libertades; el rechazo no es más que resistencia a la totalización de la politica.

La insurrección en la que se pronuncia el rechazo anónimo e impersonal, de la que Blanchot hablará incluso antes del acontecimiento de mayo del 68, afirma esta fuerza del rechazo como momento de ruptura con la historia, pero también de ruptura con todo principio organizativo, representativo y activo de la sociedad. La exigencia será la inorganización de la multitud en su impotencia; lo esencial, la dispersión.

\section{Revolución}

El rechazo afirma una ruptura con el poder. Un texto sin firma y sin título, seguramente escrito durante mayo del 68 , señala la apuesta política de ese momento: 
El objetivo último, es decir, también inmediato, evidente, es decir, escondido, directo-indirecto: afirmar la ruptura. Afirmarla: organizarla volviéndola cada vez más real y más radical.

¿Qué ruptura? La ruptura con el poder, por tanto, con la noción de poder [...] [con] nuestra concepción incluso de la oposición al poder, cada vez que esta oposición se constituye en partido de poder (Blanchot, 2001, 111).

Esta ruptura con el poder, y es aquí donde se concentra la apuesta de Blanchot, debe ser al mismo tiempo una ruptura del poder. Blanchot plantea un principio de insurrección que no busca ni tomar el poder ni simplemente transformarlo, sino que se afirma como el gesto mismo de interrupción. «Poner en claro el rasgo singular de este rechazo es una de las tareas teóricas del nuevo pensamiento político» (Blanchot, 2001, 102), sostendrá en los comités del 68. La singularidad del rechazo a la que se refiere es la de un rechazo que no pueda ser reducido a un momento negativo. Su afirmación debe permanecer irreductible a cualquier forma de negatividad. Debe romper con la dialéctica de la acción, con la economía de «las revoluciones tradicionales» - «Al contrario que en "las revoluciones tradicionales", no se trataba de tomar el poder para reemplazarlo por otro, $[\ldots]$ ni tampoco de invertir un mundo viejo», "ausencia de reacción», dirá en la sección titulada «Mayo del 68" de La comunidad inconfesable (Blanchot, 2002, 54-56)-. La declaración del rechazo es enunciada por un habla que pronuncia la indeterminación, la dispersión, que desvía y se desvía de sí misma, al menos siempre que no se "petrifique en consigna» (Blanchot, 2008, 26). En los escritos del 68, el rechazo se definirá como ruptura, discontinuidad. Habla que se sustrae del curso de la historia ${ }^{7}$, como también del discurso, del libro, destinándose así a la «ausencia de libro», a la desobra ${ }^{8}$.

En mayo del 68, este momento de interrupción no presenta nada más que un «ser-juntos» (Blanchot, 2002, 55), y este ser-juntos desmorona por sí mismo y no de manera reactiva lo instituido, «reduciendo a lo insignificante todo poder

\footnotetext{
7 «Eso tuvo lugar. La decisión de una discontinuidad radical y, podemos decir, absoluta cayó, separando, no dos periodos de la historia, sino la historia y una posibilidad que ya no le pertenece más directamente». BLANCHOT, M. (2001). Escritos politicos, trad. cit., p. 130.

${ }^{8}$ «Nunca escribiremos sobre lo que tuvo lugar, no tuvo lugar, en mayo [...]. Admitimos que este rechazo es uno de los puntos en los cuales la escritura y la decisión de ruptura se encuentran: una y otra siempre inminentes y siempre imprevisibles». BLANCHOT, M. (2001). Escritos politicos, trad.cit., pp. 110-111.
} 
ya organizado, suspendiendo cualquier posibilidad de reorganización» (Blanchot, 2008, 26). Rompe con todo principio de reconocimiento y de mediación, y da cuenta al mismo tiempo de una soberanía que se hurta a la aprehensión del poder, señalando su ruina. Los términos espontaneidad e inocencia, que se asocian respectivamente a decisión y transgresión, dan cuenta de ello.

Tanto en los escritos del 68 como en La comunidad inconfesable la decisión del rechazo se relaciona con la espontaneidad. "A esta decisión del rechazo que no es un poder, ni poder de negar, ni negación en relación con una afirmación previamente planteada o proyectada, a ella se la nombra cuando se hace intervenir, en el proceso 'revolucionario', la espontaneidad» (Blanchot, 2001, 102) ${ }^{10}$. Frente al "proceso revolucionario" tradicional, con sus fines y medios, la decisión inminente a la que Blanchot alude es la decisión como apertura a lo imprevisible, decisión del abandono. En La comunidad inconfesable, es la comunicación la que se denomina, entre comillas, "espontánea», como "efervescencia casi pura» (Blanchot, 2002, 55), abandonando el cálculo, el dominio, descuidando de ese modo la autoridad.

La transgresión también es asociada a una fórmula que designa la falta de reconocimiento y de voluntad transgresiva. La transgresión es inocente. En 1968, en un brevísimo escrito donde cita a Benjamin, se puede leer: «El único modo de presencia de la revolución es su posibilidad real. Entonces, hay detención, suspenso. En esa detención, la sociedad se deshace de parte a parte. La ley se derrumba. La transgresión se realiza: por un instante es la inocencia; la historia interrumpida» (Blanchot, 2001, 117). En La comunidad inconfesable, la "presencia inocente» (Blanchot, 2002, 56) acompaña al desconcierto del poder ante lo

\footnotetext{
${ }^{9} \mathrm{La}$ continuidad que establecemos entre los escritos de los años 50 y 60 con los escritos posteriores, en concreto, con La comunidad inconfesable, en el artículo de GARCÉS, M. (2013). «El "comunismo de pensamiento" de Maurice Blanchot. Una lectura desde sus Escritos politicos», Isegoría no49, pp. 567-58, es cuestionada al entender que en Blanchot hay un abandono de una apuesta política revolucionaria que se transforma en los 80 en una ética-estética que a su vez se inscribe en una línea filosófica en torno a la noción de comunidad y finitud. Frente a esta hipótesis sostenemos que la apuesta política de Blanchot en ninguno de los dos periodos se dirige hacia una transformación social por medio de herramientas políticas sino que señala hacia una interrupción del poder donde la cuestión de la finitud y la escritura están siempre presentes.

${ }^{10}$ No obstante, Blanchot aclara a continuación los equívocos a los que puede conducir esta noción: «[...] con la reserva de que esta noción de espontaneidad está, desde muchos puntos de vista, sujeta a caución, y es vínculo de más de una idea dudosa - por ejemplo, una especie de vitalismo, de autocreatividad natural, etc.» .
} 
que escapa a su dominio. La decisión del rechazo a asumir un poder, «rechazo instintivo» (Blanchot, 2002, 57), no es más que una "declaración de impotencia» (Blanchot, 2002, 57) que no obstante es una "potencia suprema» (Blanchot, $2002,58)$ pues no es dictada por un acto en el que quede disuelta, sino que más bien se entrega o se abandona a la impotencia, como potencia impotente: "presencia del "pueblo" en su potencia sin límites que, para no limitarse, acepta no hacer nada. [...] Potencia suprema, ya que incluía, sin sentirse disminuida, su virtual y absoluta impotencia» (Blanchot, 2002, 58) ${ }^{11}$.

Y sin embargo, ahí donde parece que no hay más que entrega a la desobra, pues nada se efectúa, se construye o se constituye en este tiempo de la interrupción, Blanchot ya afirmaba en el 68 y volverá a hacerlo en La comunidad inconfesable, algo se construye, algo se reinventa. En el 68, con un guion pone en relación esta doble vertiente: «destruir-construir» (Blanchot, 2001, 105). En La comunidad inconfesable, describe un doble movimiento cuando se refiere al pueblo. Por una parte, se produce «la disolución del hecho social» (Blanchot, 2002, 59); por otra parte, se da «la recalcitrante obstinación en reinventar este [el hecho social] en una soberanía que la ley no puede circunscribir, puesto que la recusa al tiempo que se mantiene como su fundamento» ${ }^{12}$. El «hecho social» no se destruye o se disuelve sin que se construya o se reinvente de otro modo, como fundamento de la ley que recusa, y que el pueblo desatado del lazo del contrato recusa soberanamente, como «insurrección soberana». Construir o reinventar es en este caso otra manera de decir, «no instituir, no instituirse»; poner la ley «en relación»- o siguiendo la crítica de Nancy habría que decir en «no-relación»-con un afuera.

\footnotetext{
${ }^{11}$ En torno a la noción de impotencia, se han realizado aproximaciones entre la obra de Blanchot y Agamben. Subrayando la divergencia entre el pensamiento de Blanchot y los de Benjamin y Agamben, remitimos a HILL, L. (2007). "Not in our name”: Blanchot, politics, the neuter», Paragraph, vol. 30, no3: Blanchot's epoch, pp. 141-159. Sobre las afinidades y divergencias WALL, Th. (1999). Radical Passivity, Nueva York: State University of New York Press. Estableciendo un vínculo, aunque no explicito desde la noción de ergon, MANCHEV, B. (2014). "Maurice Blanchot et la politique de l'impossible», Lignes: Les politiques de Maurice Blanchot 1930-1993, pp. 196-215.

${ }^{12}$ Traducción tomada de NANCY, J.-L. (2015). La comunidad descalificada, trad. de Cristina de Peretti y Cristina Rodríguez Marciel, Madrid: Avarigani, p. 89.
} 


\section{Política por el rechazo}

En La comunidad descalificada Nancy realiza una lectura detallada de $L a$ comunidad inconfesable. Se detiene en diferentes elementos de este libro que fundamentalmente se reúnen en torno a dos ejes enlazados entre sí: la comunidad de los amantes y la política. Su crítica se resume en las últimas palabras de su libro (antes de la "coda»): "Cualquier ontología que con anterioridad al ser no se remonte a la relación es demasiado exigua. Y cualquier política que pretenda fundarse en una ontología es demasiado amplia» (Nancy, 2015, 158). Esta conclusión remite a una referencia mutua entre la política y la comunidad, la primera encontrando un fundamento en la segunda. Pero restrigiéndose a la política, es también posible seguir la objeción que Nancy propone ${ }^{13}$.

Una frase de la sección «Mayo del 68» llama especialmente la atención de Nancy: «Presencia inocente, "común presencia" (René Char), que ignora sus límites, política por el rechazo a no excluir nada y la conciencia de ser, tal cual, lo inmediato-universal» (Blanchot, 2002, 56). Esta "presencia inocente», compuesta por cualquiera sin distinción, donde, continúa el texto, «todo se aceptaba» (Blanchot, 2002, 56), donde se daba «la imposibilidad de reconocer un enemigo» (Blanchot, 2002, 56) ${ }^{14}$, se define como «política». Se trata de una política ilimitada, ni instituida ni instituyente (sin proyecto), que en el texto aparece como irreductible a otra política, una política limitada, asociada al Estado, a las leyes, a lo constituido que emana del poder. Esta doble política implica según la interpretación de Nancy una anfibología del término "política» en la que Blanchot quedaría atrapado. Tal anfibología corresponde a una doble acepción de este término, una que se limitaría a un registro político, otra que atendería a un registro ontológico, incluso teológico (Nancy, 2015, 55). La política ilimitada, la "presencia del pueblo" que era aquella que en su soberanía recusaba la ley manteniéndose como su fundamento, presentaría, declararía, una verdad

\footnotetext{
${ }^{13}$ En Cahiers Maurice Blanchot no4, inv. 2015/2016, Dijon: Les presses du réel, una sección ha sido dedicada a la lectura de La comunidad descalificada de Nancy. Entre los escritos reunidos, destacamos por la proximidad temática el artículo de Juan Manuel Garrido y Aïcha Liviana Messina «Politique au-delà du politique. Le cœur et la loi de l'exigence communitaire chez Nancy et Blanchot», pp. 188-204.

${ }_{14}$ Esta imposibilidad de reconocer al enemigo señala una ruptura con la lógica política de Schmitt. Para una comparativa entre ambos autores, véase GALINDO HERVÁS, A. (s. f.). «Estar dormido o estar durmiendo. Blanchot y lo político», Biblioteca Saavedra Fajardo de pensamiento político, recurso electrónico disponible en http://www.saavedrafajardo.org/ Archivos/Trabajos/TRAB006-AGH.pdf
} 
política, la verdad de la política, inaccesible, inalcanzable, para toda política que para serlo no podría dejar de instituirse y que en este sentido sería, respecto a esa política primera, derivada. Así se estaría señalando un fundamento político y una jerarquía, aunque este fundamento fuera precisamente un fundamento sin fondo, sin poder para fundarse, acontecimiento efímero que no pudiera instituirse más que en lo efímero de su tener lugar. Una política sin política donde el sin sería ese lugar vacío que debe permanecer preservado -Nancy dirá sacralizado- y que lleva el nombre de lo inconfesable ${ }^{15}$.

En la presentación de La comunidad descalificada, Cristina Rodríguez expresa en pocas palabras la lectura de Nancy sobre esta política:

De algún modo se habría producido una hipersacralización de la política que acaso sea lo que tenga lugar cuando la política está ausente. Blanchot se refiere a una política que "no excluye nada" y cuando la política lo es "todo", como Nancy no se ha cansado de repetir, acaso se convierta en "nada" (Nancy, 2015, 21).

Esta interpretación lleva a Nancy a poner en relación esta política de Blanchot con su política de los años 30, una política referida a una instancia superior, un orden político donde lo que en realidad se ponía en juego era una verdad de la existencia. Nancy ve en Blanchot tanto la afirmación de una política imposible (¿qué clase de política podría dar cuenta de eso insubordinado que rechaza cualquier concreción y que Blanchot denomina política por el rechazo?), como la afirmación de una política de lo imposible, y en eso mítica. Pues si la política requiere de cierta concreción $-y$ es en su sentido limitado como Nancy privilegia la lectura del «sentido político acuciante» (Blanchot, 2002, 94) al que Blanchot se refiere para cerrar su libro- esta política no podría concretarse sin traicionar o sin ser de un orden completamente diverso a una verdad política jerárquicamente superior cuyo carácter no podría ser concreto o limitado. Si hubiera un régimen político que respondiera a tal política sin traicionarla sería, conjetura Nancy llevándolo a un extremo hipotético, «una forma de monarquía, de presencia individual o colegiada, de oligarquía aristocrática donde la figura soberana portaría con un único rasgo la fuerza simbólica y la desaparición de lo común»

\footnotetext{
${ }^{15}$ Nancy encuentra en la relación de los amantes que se describen en las páginas siguientes que ese régimen de fundamento hallaría su figura en el cuerpo de la mujer que se compara al del cuerpo de cristo
} 
(Nancy, 2015, 132), una política-mítica en torno a un centro tan vacío como sagrado. Refiriéndose a la comunidad de Blanchot, continúa:

Toda relación, toda comunidad y todo lo común se encuentran así descalificados: privados de "aveu", privados de confesión o privados de una declaración escrita, es decir, en el primer sentido de la palabra francesa "aveu", que es el reconocimiento por escrito de un seńor feudal por su vasallo. Que la comunidad esté desprovista de confesión o de una declaración escrita en este último sentido es lo que la sustrae a toda dominación (pero también es lo que la sustrae a toda consistencia y al reconocimiento que el señor feudal debía a su vasallo). No es admisible ninguna comunidad salvo la que se deshace y que, desvinculándose de cualquier sumisión, se desvincula también de sí misma. Queda, en una excepcional ambigüedad, lo no-común, lo perfecto insubordinado sin confesión y que soberanamente escribe. (Nancy, 2015, 133)

Que Blanchot defina la "presencia inocente, común presencia» - la comunidad - como política, no podría dejar de implicar que esta política tendría que ser de un orden completamente irreductible a una política concreta, instituida. Señalando una política en esto, se señala lo que excede la política, lo que nunca podría ser traducido al poder de institución política, de reconocimiento y de representación, pero que sin embargo dice una verdad de la política. «Política por el rechazo a no excluir nada»: una política que se debe al rechazo del poder de negar, de reconocer, de instituirse. La "presencia del pueblo», la "común presencia», la comunidad efímera de mayo del 68 , sin más consistencia que ese efímero «inmediato-universal», que no deja más rastro que la pregunta por su tener lugar, expone y declara insurrectamente esa férrea insistencia de Blanchot en el rechazo como ruptura con el poder y ruptura del poder. Una falta de fundamento como verdad de la política, una verdad de la política que no sería política sino que traza la limitación, más que el límite o articulación, de la política. 


\section{Bibliografía}

Balibar, É. (2009). «Blanchot l'insoumis», Blanchot dans son siècle, Lyon: Sens Publique, pp. 289-314.

Balibar, É. \& NANCY, J.-L. (2014). «Discussion entre Étienne Balibar et Jean-Luc Nancy», Cahiers Maurice Blanchot, n³, Dijon: Les presses du réel, pp. 20-28.

Blanchot, M. (1932 a). «Le Rajeunissement de la politique», Journal des débats, 2 de mayo, p. 1.

-(1932 b). «Les Écrivains et la politique», Journal des débats, 27 de julio, p. 1.

-(1933). «Le Marxisme contre la révolution», La Revue française, n4, 25 de abril, pp. 506-517 [reed. en Gramma, n5, 1976, pp. 53-61].

-(2001). Escritos políticos, trad. de Lucas Bidon-Chanal, Buenos Aires: Libros del Zorzal.

-(2002). La comunidad inconfesable, trad. de Isidro Herrera, Madrid: Arena Libros.

-(2008). La conversación infinita, trad. de Isidro Herrera, Madrid: Arena Libros.

-(2010). Les intellectuels en question, recopilado en La condition critique: articles 19451998, selec. de Christophe Bident, París: Cahiers NRF, Gallimard, pp. 390-416.

Bident, Ch. (1998). Maurice Blanchot. Partenaire invisible, Seyssel: Champ Vallon.

Galindo Hervás, A. (s. f.). «Estar dormido o estar durmiendo. Blanchot y lo político», Biblioteca Saavedra Fajardo de pensamiento político, recurso electrónico disponible en http://www.saavedrafajardo.org/Archivos/Trabajos/TRAB006-AGH.pdf

GarcÉs, M. (2013). «El "comunismo de pensamiento" de Maurice Blanchot. Una lectura desde sus Escritos politicos», Isegoría n49, pp. 567-58.

Garrido, J. M. \& Messina, A. L. (2016). «Politique au-delà du politique. Le cœur et la loi de l'exigence communitaire chez Nancy et Blanchot», Cahiers Maurice Blanchot nº, Dijon: Les presses du réel, pp. 188-204.

HiLl, L. (2007). «"Not in our name": Blanchot, politics, the neuter», Paragraph, vol. 30, n³: Blanchot's epoch, pp. 141-159.

-(2014). «Pour une politique du fragmentaire», Cahiers Maurice Blanchot nº3, Dijon: Les presses du réel, pp. 50-60.

Loubet del Bayle, J.-L. (1969). Les Non-Conformistes des années 30, París: Seuil.

Martínez GonzÁlez, R. (2014). Maurice Blanchot: la exigencia politica, Zaragoza: Prensas Universitarias.

Mesnand, Ph. (1996). Maurice Blanchot. Le sujet de l'engagement, París: L'Harmattan. 
Manchev, B. (2014). «Maurice Blanchot et la politique de l'impossible», Lignes: Les politiques de Maurice Blanchot 1930-1993, pp. 196-215.

Nancy, J.-L. (2001). Maurice Blanchot. Passion Politique, París: Galilée.

-(2015). La comunidad descalificada, trad. de Cristina de Peretti y Cristina Rodríguez Marciel, Madrid: Avarigani.

-(2016). Que faire, París: Galilée.

SuRYa, M. (2015). L'autre Blanchot, París: Gallimard.

VerdÈs-Leroux, J. (1996). Refus et violences, París: Gallimard.

WaLL, Th. (1999). Radical Passivity, Nueva York: State University of New York Press.

Recibido : $13 / 10 / 2016$

Aceptado : 16/12/2016

\section{(C) (1) (3)}

ENDOXA está bajo una licencia de Creative Commons Reconocimiento-NoComercial-SinObraDerivada 4.0 Internacional 